\title{
Effects of Cytokinin on in vitro Propagation of Bauhinia variegata $\mathrm{L}$.
}

\author{
Belai Meeta Suwal Singh
}

\section{ABSTRACT}

Mature seeds of Bauhinia variegata $L$ were cultured on half strength Murashige and Skoog medium. For experimentation, nodal cuttings were used as explants from in vitro growing plants. Cytokinin, N-benzyl-9-(2tetrahydropyranyl) (BPA), kinetin(6-furfurylaminopurine), zeatin, 6-(4hydroxy-3-methyl-trans -2-butenyl amino purine), 2- isopentenyl amino purine (2-ip), and benzylaminopurine (BAP) were tested for best propagation. Well grown plants were achieved in medium supplemented with $5 \mu \mathrm{M}$ BPA and $0.5 \mu \mathrm{M}$ BAP. The propagated plants were acclimatized very well after transferred to the field.

Keywords: MS medium, nodal culture, BPA, Kinetin, Zeatin, 2-ip and BAP.

\section{INTRODUCTION}

Bauhinia variegata $\mathrm{L}$. is medium sized tree with strong trunk and dark grey or brown bark, measuring about 5-10 m in height. Leaves are deciduous measuring $10-15 \mathrm{~cm}$ long and deeply cordate. Flowers are large fragrant with white or purplish petals (Fig. 1 A) The tree blooms during March to April and fruits are matured in September to November. $B$. variegata is cultivated at an elevation of 1600 meters on loamy soil. The wood is used for making agriculture implements and for fuel, curry and pickles are prepared from flowers and buds. Decoction of young leaves is used to cure stomach trouble. The bark is used as tonic, astringent, skin diseases, ulcers and in scrofula. Dried buds are used in dysentery, piles, diarrhea, and worms. Decoction of root is used in dyspepsia in the snake poisoning [1]. An emulsion of the bark made with rice water is given with a little ginger in scrofulous enlargement of the gland of neck. A decoction of the root is a valuable drink for reducing corpulence [2].

Due to haphazard cutting of the tree, the plants are decreasing day by day. Mostly, legumes trees have traditionally been difficult to regenerate from cell culture. However, multiplication of Albizzia have been successful [3]. Micropropagation of Bauhinia purpurea was performed from stem cutting $(1.0 \mathrm{~cm})$ of mature tree on MS medium with $5 \mu \mathrm{M}$ kinetin [4], [5]. Regeneration of B. vahlii from nodal segments of mature lianias on MS medium supplemented with $2.5 \mu \mathrm{M}$ kinetin plus $100 \mathrm{mg} / \mathrm{l}$ adenine sulphate [6]. Multiple
Published Online: November 28, 2020

ISSN: $2684-5199$

DOI :10.24018/ejbio.2020.1.6.123

Belai Meeta Suwal Singh* Department of Botany, Patan Multiple Campus, Patan Lalitpur, Nepal. (e-mail: belaisingh@gmail.com)

*Corresponding Author shoots were produced in Acacia mearnsii from nodal explants on MS medium supplemented with $2.0 \mathrm{mg} / \mathrm{l} \mathrm{BAP} \mathrm{[7].}$

The main aim of this study is to develop the protocol for the micropropagation of Bauhinia variegata using different cytokinin.

\section{MATERIALS AND METHODS}

Healthy seeds were collected from the elite plants grown in Dakshinkali area South of Kathmandu valley. The seeds were brought to the laboratory of Institute of Pharmacognosy, Vienna, Austria and stored in refrigerator at $4{ }^{\circ} \mathrm{C}$ until use where the laboratory research work was performed. Seeds were soaked in distilled water with few drops of Tween 20 for an hour and washed three times with sterilized distilled water and surface sterilized by rinsing in 30\% ethanol for $10 \mathrm{~min}$, followed by treatment of $10 \%$ sodium hypoclorite for 10 minutes and then rinsed three times with sterilized distilled water. The sterilized seeds were implanted on half strength MS medium. The $\mathrm{pH}$ of the medium was adjusted to $5.8 \pm 1$ before autoclaving at $121{ }^{\circ} \mathrm{C}$ for 20 minutes. The media was solidified by adding $0.8 \%$ bacteriological agar.

The nodal explants $(1 \mathrm{~cm}$ long) were excised from in vitro germinated seedlings (Fig. 1 B) The explants were subcultured on MS medium plus $0.5 \mu \mathrm{M}$ BAP to have more nodal explants for experimentation. The different cytokinin N-benzyl-9-(2-tetrahydropyranyl) (BPA), kinetin(6furfurylaminopurine), zeatin, 6-(4-hydroxy-3-methyl-trans -2butenyl amino purine), 2- isopentenyl amino purine (2-ip), 
and benzyl amino purine (BAP) were used at four different concentrations $(0.5,1.0,2.0$. and $5.0 \mu \mathrm{M})$ incorporated separately into MS basal medium respectively in $200 \mathrm{ml}$ capacity with $40 \mathrm{ml}$ medium. In each of the vessel 4 nodal explants grown on MS medium plus $0.5 \mu \mathrm{M}$ were inoculated to have more materials. The culture was maintained at $25{ }^{\circ} \mathrm{C} \pm 4{ }^{\circ} \mathrm{C}$ under a photoperiod of $16 \mathrm{~h}\left(40 \mu \mathrm{mol} . \mathrm{m}^{-}{ }^{2} \mathrm{~s}^{1}\right.$ supplied by OSRAM Biolox tubes) in the growth chamber with a level of $70 \%$ relative humidity. The results were taken after 8 weeks of inoculation. All the results obtained were worked out statistically with SPSS, a system of analytical procedure.

\section{RESULTS}

\section{A. Effects of BPA}

The explants implanted on MS medium supplemented with $0.5 \mu \mathrm{M}$ BPA showed 6.50 nodes, elongation of shoot 57.25 $\mathrm{mm}$ and calli proliferations $10.30 \mathrm{Q}(\mathrm{mm})$ (Fig. 1 C). Hormones 1.0 to $2.0 \mu \mathrm{M}$ BPA supplemented to medium produced optimum nodes as well as shoots and calli. Cultures grown on MS medium with $5.0 \mu \mathrm{M}$ BPA showed best results with 6.15 nodes and $68 \mathrm{~mm}$ shoots length and $11.30 \mathrm{Q}(\mathrm{mm})$ calli. The plants grown on MS plus BPA produced very healthy plants with natural sized leaves and rigid stem. They could be easily processed for further propagation and subcultures.

\section{B. Effects of $K n$}

The nodal explants grown on MS medium supplemented with different concentrations of $\mathrm{Kn}$, exhibited shoot differentiation from nodes and moderate growth in shoot length. On MS medium supplemented with $0.5 \mu \mathrm{M} \mathrm{Kn}$ showed 4.50 nodes and 22-mm shoot lengths with $10.30 \mathrm{Q}$ (mm) calli. On MS medium supplemented with $2.0 \mu \mathrm{M} \mathrm{Kn}$ showed only 3.80 nodes and $23.20 \mathrm{~mm}$ shoot length with 1.20 $\mathrm{Q}(\mathrm{mm})$ calli and however with $5.0 \mu \mathrm{M} \mathrm{Kn}$ showed only 3.80 nodes and $22.80 \mathrm{~mm}$ shoot length with $8.90 \mathrm{Q}(\mathrm{mm})$ calli. The explants proliferated into calli up to $6-9 \mathrm{Q}(\mathrm{mm})$. Increased mass of calli was observed with increase in the concentrations of $\mathrm{Kn}$.

\section{Effects of Zeatin}

MS medium supplemented with $0.5,1.0$ and $2.0 \mu \mathrm{M}$ Zeatin (Zin) showed very poor propagation of nodes 3.70 and shoot length measured 14-17 $\mathrm{mm}$ with very few amounts of calli 4 - $5 \mathrm{Q}(\mathrm{mm})$. But high concentration 5.0 $\mu \mathrm{M}$ Zin showed slightly better response with 4.40 nodes and $33.60 \mathrm{~mm}$ shoot lengths with $8.05 \mathrm{Q}(\mathrm{mm})$ calli (Fig. $1 \mathrm{D})$. The plants produced on MS medium in combination with Zin showed stunted plants with least development of leaves and weak stem.

\section{Effects of 2-iP}

In lower concentration of 2- isopentenyl amino purine (2ip), few nodes were formed. As the concentration of 2-iP increased the number of node formation were also increased. On MS medium supplemented with 2-iP, showed optimum differentiation of the nodes as well as the growth of shoot length with few amounts of calli masses. On MS medium supplemented with $5.0 \mu \mathrm{M} 2$-iP propagated 4.40 nodes and $39.55 \mathrm{~mm}$ shoot lengths with $8.05 \mathrm{Q}(\mathrm{mm})$ calli. The plants obtained on MS plus 2-iP were not healthy and rigid for propagation (Fig. $1 \mathrm{E}$ ).

\section{E. Effects of BAP}

MS medium supplemented with BAP showed very good response in growth of nodal explants. MS medium supplemented with $0.5 \mu \mathrm{M}$ BAP showed best multiplication of nodes (6.25) as well as shoot lengths $(52.80 \mathrm{~mm})$. The propagated plants at other remaining concentrations of 1.0 , 2.0 and $5.0 \mu \mathrm{M}$ were also observed with good response. Medium with $0.5-5.0 \mu \mathrm{M}$ BAP, the calli formations observed were in the range of $9-16 \mathrm{Q}(\mathrm{mm})($ Fig. $1 \mathrm{~F})$.

\section{F. Control}

MS control medium (without hormone) showed 3.85 nodes and shoot length measured $18.20 \mathrm{~mm}$. The plants obtained were moderate sized and there was no development of callus in the control (Fig.1. G, Table 1).

\begin{tabular}{|c|c|c|c|}
\hline $\begin{array}{c}\text { Additive/s in } \\
\text { Media } \\
(\mu \mathrm{M})\end{array}$ & $\begin{array}{c}\text { Number of } \\
\text { nodes/culture } \\
\text { Mean } \pm \text { SE }\end{array}$ & $\begin{array}{l}\text { Shoot length }(\mathrm{mm}) \\
\text { Mean } \pm \text { SE }\end{array}$ & $\begin{array}{c}\text { Q Calli }(\mathrm{mm}) \\
\text { Mean } \pm \text { SE }\end{array}$ \\
\hline \multicolumn{4}{|c|}{ BPA } \\
\hline 0.5 & $6.50 \pm 0.4$ & $57.25 \pm 3.5$ & $10.30 \pm 0.4$ \\
\hline 1.0 & $5.80 \pm 0.5$ & $43.45 \pm 3.4$ & $8.75 \pm 0.4$ \\
\hline 2.0 & $4.40 \pm 0.3$ & $38.35 \pm 2.2$ & $10.20 \pm 0.3$ \\
\hline 5.0 & $6.15 \pm 0.4$ & $68.00 \pm 7.0$ & $11.30 \pm 0.4$ \\
\hline \multicolumn{4}{|c|}{$\mathrm{Kn}$} \\
\hline 0.5 & $4.50 \pm 0.2$ & $22.00 \pm 1.8$ & $6.55 \pm 0.4$ \\
\hline 1.0 & $4.25 \pm 0.3$ & $22.15 \pm 1.5$ & $7.65 \pm 0.4$ \\
\hline 2.0 & $3.80 \pm 0.3$ & $23.20 \pm 2.0$ & $8.45 \pm 0.4$ \\
\hline 5.0 & $3.80 \pm 0.2$ & $22.80 \pm 2.0$ & $8.90 \pm 0.4$ \\
\hline \multicolumn{4}{|c|}{ Zin } \\
\hline 0.5 & $3.70 \pm 0.2$ & $14.65 \pm 0.8$ & $4.90 \pm 0.4$ \\
\hline 1.0 & $3.70 \pm 0.2$ & $14.90 \pm 0.5$ & $5.65 \pm 0.2$ \\
\hline 2.0 & $3.70 \pm 0.2$ & $17.30 \pm 1.1$ & $5.65 \pm 0.3$ \\
\hline 5.0 & $4.40 \pm 0.3$ & $33.60 \pm 3.3$ & $12.15 \pm 1.7$ \\
\hline \multicolumn{4}{|c|}{ 2-Ip } \\
\hline 0.5 & $3.25 \pm 0.5$ & $29.30 \pm 5.5$ & $5.20 \pm 0.5$ \\
\hline 1.0 & $4.30 \pm 0.3$ & $33.45 \pm 3.9$ & $1.90 \pm 0.6$ \\
\hline 2.0 & $3.30 \pm 0.3$ & $32.30 \pm 5.6$ & $5.00 \pm 0.6$ \\
\hline 5.0 & $4.40 \pm 0.2$ & $39.55 \pm 4.5$ & $8.05 \pm 1.0$ \\
\hline \multicolumn{4}{|c|}{ BAP } \\
\hline 0.5 & $6.25 \pm 0.3$ & $52.80 \pm 3.0$ & $9.95 \pm 0.5$ \\
\hline 1.0 & $4.75 \pm 0.3$ & $46.80 \pm 2.8$ & $9.25 \pm 0.5$ \\
\hline 2.0 & $4.65 \pm 0.3$ & $51.35 \pm 4.8$ & $11.65 \pm 0.4$ \\
\hline 5.0 & $4.20 \pm 0.3$ & $38.00 \pm 3.3$ & $16.75 \pm 0.7$ \\
\hline Control & $3.85 \pm 0.2$ & $18.20 \pm 1.3$ & $0.00 \pm 0.0$ \\
\hline
\end{tabular}

The eight weeks old healthy Bauhinia plants grown in vitro were removed from the culture medium and washed carefully in tap water to remove some traces of nutrient medium and agar. The plastic trays were filled with soil (Humus-Ton Substrate N8) with sand in 1:1 ratio and kept in mist chamber for hardening. The acclimatizing substrate was disinfected using benlate and previcure. The humidity inside the mist chamber was maintained at $80-90 \%$ for a week and then reduced up to $70 \%$ in second week. The well-rooted acclimatized plants were transferred to green house for further hardening and acclimatization. 

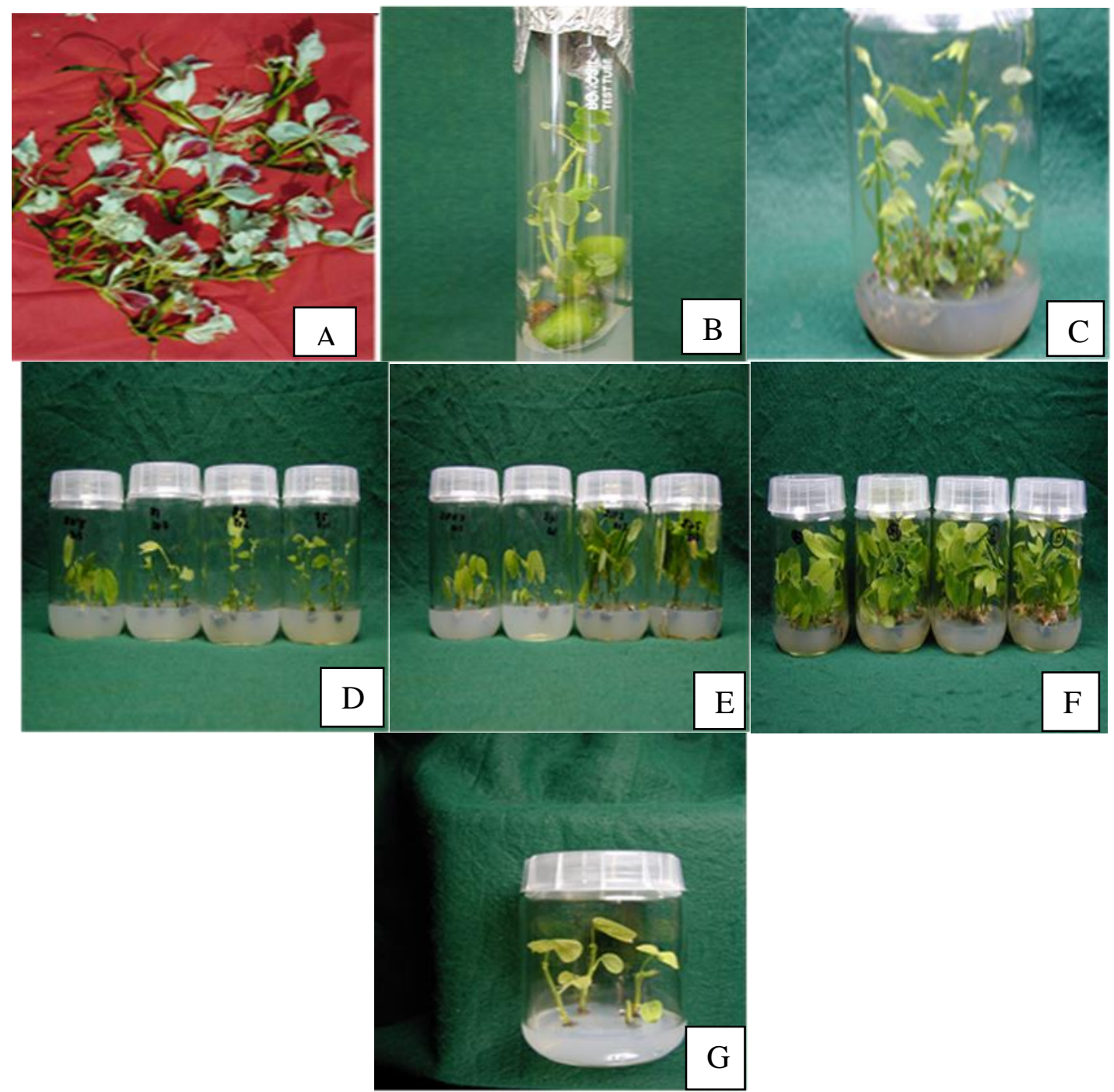

Fig. 1. (A-G). A. Flowers of Bauhinia variegata; B. In vitro grown seedling; C. MS medium with 5.0 $\mu \mathrm{M}$ BPA; D. MS medium with $0.5,1.0,2.0$ and $5.0 \mu \mathrm{M}$ Zin right to left respectively; E. MS medium with $0.5,1.0,2.0$ and $5.0 \mu \mathrm{M} 2$-iP right to left respectively; F. MS medium with $0.5,1.0,2.0$ and $5.0 \mu \mathrm{M}$ BAP right to left respectively; G. Control MS basal medium.

\section{DISCUSSION}

Regarding multiple shoot regeneration, the use of nodal portion as explant was found most suitable for the micropropagation of $B$. variegata and among all the cytokinin used the multiplication was recorded maximum on MS medium supplemented with $0.5 \mu \mathrm{M}$ BPA and $5.0 \mu \mathrm{M}$ BPA. In the present investigations, different sources of cytokinin was tested for the propagation of B. variegata. Many researchers have tried in cytokinin for the propagation of shoots in different plants in vitro culture but only few researchers have worked using BPA.

Relatively few reports are available on micropropagation of Bauhinia species in tissue culture. Regeneration of Bauhinia vahlii were successful using seedling explants on MS medium supplemented with thidizuron and kinetin $1.0 \mu \mathrm{M}$ each [8].

In vitro propagation for $B$. variegata and Parkinsonia aculeata has successfully conducted from nodal explants of mature trees on MS medium with 13.3 $\mu \mathrm{M}$ BAP [9]. Using
MS medium with $5.0 \mu \mathrm{M}$ kinetin micropropagation of $B$. purpurea have been successful from stem cutting of mature trees.

Similarly, on MS medium supplemented with $9.0 \mu \mathrm{M} 2,4-$ $\mathrm{D}$ and $4.65 \mu \mathrm{M}$ kinetin for the development of somatic embryo in Acacia farneciana and A. shaffneri from immature zygotic embryo was done [10]. Artocarpus altilis was tried from mature plant material on zeatin $2.2 \mu \mathrm{M}$ [11]. But in the present findings the above concentrations of kinetin, zeatin and 2-iP used for the protocol development for micropropagation of $B$. variegata was not found satisfactory.

Multiple shoots were obtained in Kalmia latifolia in liquid woody plant medium (WPM) supplemented with $8 \mu \mathrm{M} 2$-iP [12]. Whereas B. variegata was propagated on MS medium supplemented with $1.0 \mu \mathrm{M}$ BAP with $0.05 \mu \mathrm{M}$ NAA [13]. Multiple shoots of Acacia nilotica were produced from cotyledonary node explants on $B_{5}$ medium with $1.5 \mathrm{mg} / \mathrm{l} \mathrm{BA}$ [14], [15]. In the same way, the shoots of Albizia falcatoria were regenerated and multiplied from cotyledonary explants 
on MS medium with $4.4 \mu \mathrm{M}$ BA [16]. Multiple shoots of Acacia mearnsii were produced from nodal explants on MS medium supplemented with $2.0 \mathrm{mg} / 1$ BAP [7]. Propagation of Dalbergia sissoo Roxb. was successful when cultured on MS medium supplemented with $1.0 \mathrm{mg} / \mathrm{l} \mathrm{BAP}$ and $0.1 \mathrm{mg} / \mathrm{l}$ NAA [17]. Whereas B. purpurea was propagated on MS medium supplemented with $0.5 \mu \mathrm{M} \quad$ N-benzyl-9tetrahydropyranyl for multiplication of shoots and $5.0 \mu \mathrm{M}$ Zeatin for multiplication of nodes [18]. Multiple shoot propagation of $B$. purpurea was successful from nodal explants supplemented on MS medium with $0.5 \mu \mathrm{M} \mathrm{N}$ benzyl-9-tetrahydropyranyl and $0.1 \mu \mathrm{M}$ Indole -3-acetic acid where the nodes 6.50 and the shoot length $54.70 \mathrm{~mm}$ were recorded [19]. But in present finding in the concentrations of $5.0 \mu \mathrm{M}$ BPA alone produced 6.50 nodes and $57.25 \mathrm{~mm}$ shoot lengths. Whereas, in the $0.5 \mu \mathrm{M}$ BAP the node formation 6.25 and the shoot length $52.80 \mathrm{~mm}$ were recorded.

\section{CONCLUSION}

So, it can be concluded that the results obtained in the concentration 5.0 $\mu \mathrm{M}$ BPA were found the best for protocol development for micropropagation of B. variegata and can be applicable for large scale production.

\section{ACKNOWLEDGEMENTS}

Prof. Dr. Brigitte Kopp and Dr. Cristoph Wawrosch of Institute of Pharmacognosy, University of Vienna and Prof. Dr. Sanu Devi Joshi, former Head, Department of Botany, Tribhuvan University is duly acknowledged for providing the necessary supports. The Austrian Academic Exchange Service (ÖAD), Vienna Austria is also acknowledged for financial support.

\section{REFERENCES}

[1] P. N. Suwal. Medicinal plants of Nepal. His Majesty Government of Nepal, Department of Medicinal Plants, Thapathali, Kathmandu. 1970. pp. 33-34.

[2] J. F. Dastur, F. N. I. Medicinal plants of India Pakistan. D.B. Taraporevala Sons \& co. private Ltd. 1962. Pp. 33-34.

[3] P. K. Gharyal and S. C. Maheshori. Differentiation in explant from mature leguminous trees. Pl. Cell Rept. Vol. 8: pp. 550-553.

[4] A. Kumar. Micropropagation of a mature leguminous tree- Bauhinia purpurea. Pl. Cell Tiss. and Org. Cult. 1992.vol. 31: pp. 257-259.

[5] T. Murashige and F. Skoog. A revised medium for rapid growth and bioassays with tobacco tissue cultures. Physiol. Plant. 1962. Vol. 15: pp. 473-497.

[6] J. Upreti and U. Dhar. Micropropagation of Bauhinia vahlii Wight and Arnott-A leguminous liana. Pl. Cell Rept.1996. vol. 16: pp. 250-254.

[7] S. L. Beck, R. Dunlop and J. V. Staden. Micropropagation of Acacia mearnsii from ex vitro material. Pl. Gr. Regul. 1998 vol. 26: pp. 143148.

[8] I. D. Bhatta, and U. Dhar. Combined effect of cytokinin on multiple shoot production from cotyledonary node explants of Bauhinia vahlii. Pl. Cell Tiss. and Org. Cult. 2000.vol. 62: pp. 79-83.

[9] J. Mathur and S. Mukunthakumar. Micropropagation of Bauhinia variegata and Parkinsonia aculeata from nodal explants of mature trees. Pl. Cell Tiss. and Org. Cult. 1992. Vol. 28: pp.119-121.

[10] B.O.C. Ortiz, M. E. P. Reyes and E. P. M. Balch. Somatic embryogenesis in Acacia farnesiana and Acacia schaffneri. In Vitro Cell Dev Biol-Plant. 2000. Vol. 36: pp. 286-272.
[11] J. R. Miller and J. E. Ducan. In vitro propagation of Artocarpus altilis (Park) Forberg (Breadfruit) from mature plant material. In Vitro Cell Dev Biol-Plant .2000. vol. 36: pp.115-117.

[12] G. B. Lloyd \& McCown B. M. Commercially feasible micropropagation of mountain laurel (Kalmia latifolia) by use of shoot tip culture. Comb. Proc. Int. Plant Propagators Soc. 1981. Vol. 30: pp. 421-437.

[13] B. M. Singh, C. Wawrosch, S. D. Joshi and B. Kopp. Micropropagation of Bauhinia variegata L. from tissue culture. Nepal J. of Sc. and Tech. 2012. Vol. 13(1): pp. 39-41.

[14] A.K. Dewan, K. Nanda and S. C. Gupta. In micropropagation of Acacia nilotica subsp. Indica brenan via cotyledonary nodes. Pl. Cell Rept. 1992. Vol.12: pp. 18-21.

[15] O. L. Gamborg, R. A. Miller and K Ojima. Nutrient requrements of suspension culture of soybean root cells. Exp. Cell. Res. 1968. Vol.50: pp. 151-158.

[16] R. K. Singh and R. Mallick. Regeneration and multiplication of shoots in Albizia falcatoria. Pl. Cell Tiss. and Org Cult. 1993. vol. 32: pp. 259-261.

[17] B. Suwal, A. Karki and S. B. Rajbhandary. The in vitro proliferation of forest trees1. Dalbergia sissoo Roxb. Ex DC. Silvae Genetica. 1988. vol. 37(1): pp. 26-28.

[18] B. M. S. Singh. "Effects of cytokinins on in vitro culture of Bauhinia purpurea L. Eur. J. of Med. Pl. 2020. vol. 31(10): pp. 161-166.

[19] B. M. S. Singh. "Effects of N-Benzyl -9-(2-tetrahydropyranyl) and Indole -3-Acetic Acid in Vitro Culture of Bauhinia purpurea L.", Int. J. of Sc. Res. in Sc. and Tech. 2020. Vol. 6 (3): pp. 238-242. 